\title{
Changing Police Personal Safety Training Using Scenario-Based-Training: A Critical Analysis of the 'Dilemmas of Practice' Impacting Change
}

\author{
Christopher Cushion * \\ Loughborough University, Loughborough, United Kingdom
}

This paper outlines an analysis of using Scenario-Based-Training (SBT) to change officer Personal Safety Training (PST) based on existing research evidence and reflections from supporting a National Police Agency attempting to change PST practice. SBT is interrogated in light of its underlying assumptions and situated within the ambiguities, tensions and compromises inherent within police training cultures. Using Windschitl's

OPEN ACCESS

Edited by:

Mario S. Staller,

University of Applied Sciences for Police and Public Administration in North Rhine-Westphalia, Germany

Reviewed by: Oliver Bertram,

Bundeskriminalamt, Germany Louise Porter,

Griffith University, Australia

*Correspondence: Christopher Cushion c.cushion@lboro.ac.uk

Specialty section:

This article was submitted to Educational Psychology, a section of the journal Frontiers in Education

Received: 17 October 2021 Accepted: 13 December 2021 Published: 07 January 2022

Citation: Cushion C (2022) Changing Police Personal Safety Training Using Scenario-Based-Training: A Critical Analysis of the 'Dilemmas of Practice' Impacting Change.

Front. Educ. 6:796765. doi: 10.3389/feduc.2021.796765 framework of conceptual, pedagogical, cultural, and political dilemmas this paper analyses the forces impacting using SBT to change PST. An alternative agenda for change is presented to develop skilled officers and trainers equipped with innovative pedagogies to 're-culture' PST.

Keywords: scenario-based-training, police training, officer safety, use-of-force, practice issues

\section{INTRODUCTION}

Police officers deal with potentially dangerous or violent encounters daily (Rajakaruna et al., 2017), in some cases necessitating the use of force (Di Nota and Huhta, 2019). Use of force decisions remain a source of concern for the police and the public (Andersen and Gustafsberg, 2016; Cushion, 2020; Todak and James, 2018; inter-alia). To deal with volatile and violent encounters that present "complex, multi-faceted and sometimes subtle problems' (Waddington et al., 2006, p. 182), police officers are trained in arrest and self-defence skills-known in the United Kingdom as Personal Safety Training (PST). However, PST has been subject to criticism in terms of content, delivery, and effectiveness (Waddington et al., 2006; Renden et al., 2015b; Cushion, 2020), with recognition that this training needs to be 'overhauled' (College of Policing 2020). Rather than specific techniques or 'system', the 'what' of PST, this paper focusses on the 'how', or pedagogy, which currently aligns with a 'traditional' model of police training (cf. Cushion, 2020). This is "a behavioral and militaristic model of training rooted in obsolete and counter-productive practices long ago abandoned by educators and other occupational and professional communities" (Cleveland and Saville, 2007, p. 3) that is recognizable in the United Kingdom and internationally. A training model that, arguably, does not develop perception, judgement, decision-making, critical thinking, or competence (cf. Rajakaruna et al., 2017). An 'overhaul' of PST in the England and Wales has provided an opportunity to improve the 'traditional' delivery of police training and explore alternative pedagogical approaches to deliver innovation to police training systems that can have impact for policing that involves 'police-citizen' encounters (cf. Wolfe et al., 2019). 
The use of Scenario-Based-Training (SBT) pedagogies in police, military and other practice domains is not new (e.g., Birzer and Tannehill, 2001; Birzer, 2003; McCoy, 2006; Cleveland and Saville, 2007; Alison et al., 2013) and in police training SBT has established itself (e.g., Renden et al., 2015; Di Nota and Huhta 2019; Preddy et al., 2019), with Di Nota and Huhta (2019) referring to SBT as the "gold standard for complex motor learning for police" (p. 10). While establishing a toehold (cf. Werth, 2011; Rajakaruna et al., 2017; Bennell et al., 2020), there remain several issues with SBT's adequacy, implementation, and development (cf. Rajakaruna et al., 2017). Indeed Rajakaruna et al. (2017) point out that although Scenario-Based Training aims to enable officers to develop their skills in perception, judgement, and decision-making reviews of training demonstrate inadequacies in the way that training is delivered (e.g., Clarke and Armstrong, 2012; Morrison and Garner, 2011; Rostker et al., 2008). For example, time spent in scenarios is limited, instructors fail to provide feedback on officer performance and fail to demonstrate what constitutes effective performance (Rajakaruna et al. (2017)-in the case of the current research, these training issues are exacerbated when SBT is misunderstood, misapplied, and conceptualised within existing training frameworks-all issues explored in greater detail through the dilemmas framework.

Implementing changes to PST using SBT requires changes to current training, including acquiring new skills for officers and trainers, as well as understanding and making personal sense of learning; aligning the culture of police training with an alternative training philosophy; and dealing with the widely reported tradition and conservatism that has can work against and resist efforts to change (e.g., Karp and Stenmark, 2011; Werth, 2011; Basham, 2014; Wolfe et al., 2019; Belur et al., 2020; Shipton, 2020). No literature systematically examines the challenges faced in changing PST in the United Kingdom and little addresses these issues internationally when using innovative training practices, particularly SBT as a pedagogical approach. Research specifically considering PST (e.g., Buttle, 2007; Cushion, 2020) in the United Kingdom has not explored the articulations between police trainers, conceptual understandings, pedagogical practices, and the wider cultural and political realities of police training.

Using Windshcitl's (2002) framework of 'practice dilemmas' to build an analysis, this paper draws on existing police research in use-of-force training and SBT from the United Kingdom, Europe, North America and Australia. This is in addition to drawing on our experiences of supporting a national initiative across 43 police forces in England and Wales to change the PST curriculum and the 'train-the-trainer' training. The research does not focus on the local issues of a particular cohort of police trainers but looks across PST training more broadly in terms of research and practice. Analysing training practice, and the implementation of change, represents something of the ambiguities, contradictions and compromises of the endeavor. In this sense, 'dilemmas' (Windshitl, 2002) are aspects of trainers' (and our) experiences that impact the realization of SBT and changes to PST. The significance of this work lies in providing an analytical framework for considering critically trainers' practice and the issues impacting the implementation of SBT, offering the means through which trainers and trainer educators can examine their practice critically. Used as a heuristic, the analysis raises questions for practitioners to interrogate their own beliefs and pedagogy, conceptualize the wider social forces impacting practice, while providing signposting for policy makers to an alternative agenda for PST, trainer education and development.

\section{BACKGROUND: PERSONAL SAFETY TRAINING, LEARNING AND SCENARIO-BASED-TRAINING}

Before considering the dilemmas framework, it is worthwhile discussing something of learning, SBT and PST. There are different ways of understanding learning and these frame theories, models, and subsequent training practice. Recognising this means that what Windshcitl (2002) describes as 'intellectual anchors' are needed by academics and trainers to support thinking about police training (cf. Werth, 2011). Despite calls to structure police training according to 'adult learning principles' (e.g., recognising previous experience and knowledge, active involvement in the learning process) from evaluation studies and systematic reviews (e.g., Belur et al., 2020; Lettic, 2016; Jenkins et al., 2020; Rosenbaum and Lawrence, 2017; Shipton, 2020; Werth, 2011; inter-alia) current PST practice and pedagogy characterizes learning as 'procedural motor learning' or 'skill acquisition' (e.g., Renden et al., 2015a; Di Nota and Huhta 2019; O’Neil et al., 2019). Thinking about training this way carries underlying assumptions about learning, with a functionalist, individual and behavioural focus construed as an unproblematic process of transmission and assimilation. As Di Nota and Huhta, (2019), and O'Neil et al. (2019) inter-alia argue, this simplistic, linear view separates operational conditions and training, assuming officers are empty vessels to be filled, and trainers transmit training as a neutral media that delivers a prescribed and standardized 'curriculum' or 'toolbox'.

This conceptualization has created a dominant training paradigm for PST. Research evaluating use-of-force training (e.g., (Koedijk et al., 2019; Cushion, 2020; Staller et al., 2021), shows that officers tend to train isolated skills and techniques first, repeating repetitions of one technique at a time practiced in pairs, before moving on to practice another isolated skill-with Cushion (2020) showing that this type of training form often accounts for the largest proportion of activity in United Kingdom PST. Contemporary learning research and understanding (e.g., Soderstrom and Bjork, 2015) and research examining police training (e.g., Staller and Koerner, 2019) have challenged the assumptions of this approach. First, that 'isolation' of parts only to integrate them later in a more complex movement, or isolating the movement from the operational context, has met with criticism from evaluation studies with regards to transfer (e.g., Jager et al., 2013; Renden et al., 2014; Renden et al., 2015a; Renden et al., 2015b; Staller and Koerner, 2019). Framing isolated practices at the beginning of training dis-integrates the training, resulting in techniques being decoupled from 
decision-making and context. Research into learning (Soderstrom and Bjork, 2015) suggests such an approach may result in improvement in some performance in the immediate and short-term. However, performance gains fool trainers and learners that learning has taken place, and in police training can create powerful illusions of competence (cf. Cushion, 2020). Hence this training mode is appealing as rewards can seem to be gained immediately, reinforcing perceptions of 'effective' training. However, changes in short-term performance bear no relationship to long-term learning and transfer (Soderstrom and Bjork, 2015). Ultimately officer performance will decrease, and this has been shown to particularly be the case when training has been tested through encountering difficult and stressful conditions (Andersen and Gustafsberg, 2016; Renden et al., 2014; Renden et al., 2015a; Renden et al., 2015b). Indeed, evidence evaluating police training shows that under threatening conditions, police officer's performance decreases as training is insufficient to inhibit stimulus-driven reactions (fear of getting hit) and avoidance behaviours (Renden et al., 2014; Andersen and Gustafsberg, 2016; Cushion, 2020).

A linear or modular approach that positions techniques/skills first often results in 'end-on-end' or 'blocked' practice; reviews and evaluation studies have shown training in this way is a significant consumer, or even a waste, of training time (O'Neil et al., 2019; Bennell et al., 2020; Cushion, 2020; Staller et al., 2021). Learning requires direct and successful contact with appropriate learning tasks (Carpenter et al., 2012; Cushion, 2020) providing task engagement. If the task is too easy or too difficult, engagement will be insufficient for learning. Indeed, previous PST research (cf. Cushion, 2020; Jager et al., 2013; Renden et al., 2014, 2015b) suggests a combination of low level of engaged activity, limited number of repetitions, and ecologically weak practice conditions (lack of realism) make it less likely that police officers will perform under pressure. Learners need to accumulate experience by performing skills under complicated and realistic circumstances (cf. Andersen and Gustafsberg, 2016; Staller and Koerner, 2019). Further, in addition to 'time on task', the type of practice activities is key, with repeated experiential and realitybased practice linked to performing more effectively in use of force situations (e.g., Broome, 2011; Murray, 2004; Staller and Zaiser, 2015; Hine et al., 2018 inter-alia). Indeed, SBT has been shown to improve officer performance under pressure (e.g., Hulsof and Spapens, 2014; Renden et al., 2015b) and highfidelity (i.e., realistic) scenarios should be included in integrated de-escalation and use-of-force training (Rajakaruna et al., 2017; Staller and Koerner, 2019; Bennell et al., 2020).

SBT is a broad conceptualization of training concerned with the authentic, safe replication of the characteristics of the operational environment (Alison et al., 2013; Wollert and Quail, 2018; Jenkins et al., 2020). Research (e.g., Wheller and Morris, 2010; Wheller et al., 2013; Miller and Alexandrou, 2016) shows that 'modelling behaviours' through SBT is more likely to impact 'street-level' officer behaviour and can improve 'traditional' delivery of police training. SBT is a holistic training approach that when delivered in an authentic and consistent manner encourages learner-centred training when tactics, decision-making and problem-solving are critical
(Birzer and Tannehill, 2001; Birzer, 2003; McCoy, 2006; Cleveland and Saville, 2007; Werth, 2011; Rajakaruna et al., 2017). Indeed, reviews (e.g., Jenkins et al., 2020) and empirical research (e.g., Andersen et al., 2016) have shown that SBT when mapped onto the operational environment replicate 'real life' conditions and is effective in transferring technique and decisionmaking. Therefore, SBT develops decision-making under pressure as every practice attempt requires the learner to read the situation [people (self, colleagues, subject(s)); deal with variability (transitions, stages of escalation/ratios); and be aware of their environment (stability/variability)].

Authentic SBT is a conceptual approach, based on concepts, tactics and strategies rather than skill. The pedagogical focus switching to increasingly complex 'whole' scenarios/situations (i.e., radio-call to event resolution) (cf. Rajakaruna et al., 2017; Jenkins et al., 2020). In other words, scenarios are practiced in simplified and modified forms initially, while retaining the integrity or 'realism' of the practice conditions. The degree of simplification is led by officer skill level (Wickens et al., 2013; Bennell et al., 2020), and modification principles are used to reduce the demands on the learner, while being appropriate to skill level (Wickens et al., 2013; Jenkins et al., 2020), highlighting through the scenario what is important to learn. Isolated skill development is utilized but not isolated or front loaded before taking part in a scenario. Instead, the scenario retains 'perception and decision making' so the learner understands when and why the skill is needed. Thus, cognitive development through decision-making and tactical exploration are combined with skill-development and knowledge-development, and advanced together in meaningful and realistic practice progressed together in-context does not leave these connections to be made by the learner. This understanding provides motivation for learners, something often eroded by isolated skill development.

\section{ANALYTICAL FRAMEWORK: DILEMMAS}

Applying Windschitl's framework of dilemmas (conceptual, pedagogical, cultural and political) enables a viewing of the trainer, officer, contexts and their learning as inextricably inter-related. This provides a lens to investigate PST and SBT as constructed and embedded within training contexts. The fourpart model acts as a heuristic, moving from the individual trainer (personal and intellectual) to more abstract views of training, and the application of SBT in practice from a broader police organization and cultural/historical perspective (social and structural) (Windschitl, 2002; Cushion, 2013). This enables critical questions to be asked about trainers' beliefs and practices while understanding contextual and wider social forces. Importantly, Windschitl (2002) argues that the four dimensions capture the challenges in practice environments; the failure to attend to any one of the dimensions can compromise or doom attempts to implement "progressive pedagogies...(where)....addressing each of the dimensions is necessary but insufficient by itself to realize new visions of learning" (Winschitl, 2002, p. 132). 


\section{CONCEPTUAL DILEMMAS}

Conceptual dilemmas are rooted in trainers' understanding of learning and underlying assumptions and beliefs. Implicit assumptions about training and learning also inform their practice and the degree to which they understand and apply training pedagogies. Recent research from a range of police training settings (e.g., Shipton, 2012, 2020; Basham, 2014; Belur et al., 2020; Cushion 2020; Staller et al., 2021) suggests that police training practice and knowledge is most often developed by informal sources, particularly observation and experience (Koerner and Staller, 2020; Rajakaruna et al., 2017; Bergman et al., 2018). This results in practice based on history and tradition (Karp and Stenmark, 2011), rather than empirical evidence, with Koerner and Staller (2020) and Koerner and Staller (2019b) arguing that decisions within the 'how-dimension' of police training are less the result of professional trainer education than an (uncontrolled) effect of socialization, resulting in a selfreferenced, anecdotal approach to training practice based on 'what-works' and what trainers perceive 'gets results' (Cushion, 2020). Bruner (1999) names this 'folk pedagogies' i.e., strong views about how people learn and what is 'good' for them. Based on established 'traditional' pedagogy this sets limits to what is regarded as useful in the profession and what actions, behaviours, and attitudes are considered acceptable (Waddington, 1999; Karp and Stenmark, 2011; Beighton et al., 2015). Traditional police training pedagogy has been characterized as militaristic, instructor-centric, linear, based on behavioural education ideology, and list-orientated (e.g., Beighton et al., 2015; Basham, 2014; Cushion 2020; Staller et al., 2021; Werth, 2011; O'Shea and Bartowiak-Théron, 2019; inter-alia). Resulting in a training model and "pedagogical practices that reflect doctrinal values rather than educative values...[that] limits intellectual stimulation" (Densten cited in Ryan, 2006, p. 7-8) where police training and instructors are wedded in a "very behavioral and militaristic environment” (McCoy, 2006, p. 29).

Therefore, training ideologies are the frameworks producing and reproducing 'folk pedagogies' where practice and practitioners become "dogmatic and petrified because they are protected" and resistant to "criticism from within and without" (Piggott, 2011, p. 8). Indeed, police training is characterized by an "insular and defensive culture" that seeks to maintain the status quo, positioning "training in a traditional, technical framework" (Ryan, 2006, p. 3), where "learning is at best trivialized, at worst, never evaluated, taken-for-granted" and "is bound up in notions of liability and control" (Ryan, 2006, p. 4). Consequently, PST in the United Kingdom and beyond is guided by tradition, circumstance and external authority (cf. Buttle, 2007; Basham, 2014; Rajakaruna et al., 2017; Cushion 2020). In England and Wales police officers are currently trained in a largely off the shelf and 'stereotyped catalogue' (Waddington et al., 2006, p. 181) that fails to simulate the conditions an officer experiences in real-world encounters (e.g., Waddington et al., 2006; Cushion, 2020) a position replicated internationally (e.g., Renden et al., 2015; Andersen et al., 2016). There is little evidence supporting the efficacy of current prescribed training regimes (Waddington et al., 2006; Cushion, 2020) resulting in PST skills that do not necessarily transfer to the criterion environment of dealing with violent encounters (e.g., Jager et al., 2013; Renden et al., 2015); instead, officers struggled to apply taught techniques (e.g., Jager et al., 2013; Renden et al., 2015a).

Another outcome of 'folk pedagogy' is that trainer's abstract SBT, or parts of it, resulting in distorted understanding and inadequate application. Indeed, while recent research (e.g., Bennell., et a al., 2020; Hine et al., 2018; Di Nota and Huhta 2019) shows SBT as crucial to, and effective for, de-escalation and use-of-force training, there remain considerable conceptual and practical misunderstandings. For example, because of the dominance of a linear, process-product and 'skills' first approach to learning (Di Nota and Huhta 2019; Staller and Koerner, 2019; Cushion, 2020), scenarios typically play a relatively small part in training programs (Rajakaruna et al., 2017; Cushion, 2020; Koerner and Staller, 2020). In our experience from this project, it is not unusual to hear that 'SBT is nothing new' or 'we've been doing SBT for years'. However, typically, this means that scenarios are positioned as a tool for officers to demonstrate performance of 'pre-loaded' skills or for application 'in-context' after techniques are mastered (Koedijk et al., 2019; Cushion 2020; Staller et al., 2021). This positions scenarios at the end of a linear training sequence where they are often connected to an assessment of training (Constable and Smith, 2015). Put simply, SBT is often abstracted to a means to test skills and positioned after isolated practices have been completed. Currently, SBT is not viewed as a holistic training approach that encourages learner-centred training where skill, tactics, perception, judgement, decision-making and problem solving are critical and connected.

Drawing on evidence informed learning principles (e.g., Mayer, 2004; Kirschner et al., 2006; Cushion 2013), meaningful learning occurs when officers are connected to, and make sense of, what is to be learned, identify relevant knowledge and information, and organize it into a coherent structure integrated with their existing knowledge. Therefore, as Wolfe et al.'s (2019) evaluation study of use-of-force training demonstrates, an understanding of the purpose and outcome of skills is essential to understand their connection to strategies and tactics, particularly if officers believe they are already skilled. Just 'doing a scenario' does not guarantee connection with the to-belearned material, and guidance is required ('through' the scenario-using modification principles; 'in' the scenario-with the trainer and peers; and at the end through reflection and de-briefing) (Rajakaruna et al., 2017). Learning requires participation as well as skilful and progressive practice and instruction that shifts the focus of training from performance and assessment to skill development and learning (Rajakaruna et al., 2017)-a shift trainers in the England and Wales require support to do.

Elements of SBT have been identified within trainers' practice in the United Kingdom and internationally (e.g., Constable and Smith, 2015; Rajakaruna et al., 2017; Cushion, 2020), but intermingling with traditional approaches. Importantly, trainers in these circumstances fail to recognize or understand the contradictions in conceptions of practice and learning from SBT versus a linear, behavioural approach. In education, Davis 
and Sumara (2003) describe an 'epistemological gap', the language of an 'alternative approach' but with limited conceptual or practical understanding, while Fullan (1991) argues that for teachers (sic trainers) who attempt to implement innovative pedagogies, "it is possible to change on the surface by endorsing certain goals, using specific materials, even imitating the behavior without specifically understanding the principles and rationale for change. Moreover. . it is possible to value and even articulate about the goals of change without understanding the implications for practice" (p. 40). Evidence from police trainers around the world suggests that trainers' previous experiences serve as a screen through which new knowledge has to pass (cf. Basham, 2014; Beighton et al., 2015; O'Shea and Bartowiak-Théron, 2019; Belur et al., 2020; Koerner and Staller, 2020.). Therefore, new ideas, techniques and practices are not accepted whole-scale and changes to training come through serendipitous methods or from 'irresistible forces' (Young, 1991; Constable and Smith, 2015). 'Cherry picking' ideas that fit their beliefs, while rejecting or resisting others that are more challenging, enables PST trainers to adopt seemingly novel or original aspects of SBT, while preserving their fundamental beliefs about training and learning. In education, Hargreaves (1994) describes this as 'safe simulation', and in the United Kingdom it is common to see elements or imitations of SBT practiced with minimal disruption to training norms and traditions and police culture. Fragmented SBT based on limited or superficial understanding can result in practice mutation, where "pernicious, predictable mythology and pseudo principles" (Windschitl, 2002, p. 139) distort it.

\section{PEDAGOGICAL DILEMMAS}

Pedagogical dilemmas refer to trainers' pedagogical practice, their behaviour, practice structures, and all related activity contributing to learning environment design (Windschitl, 2002), and intersect to some degree with the other dilemmas. In particular, trainers across a range of police settings often do not realize the influence of their personal experience nor appreciate the ways in which their powerful assumptions about training guide their practice (Werth, 2011; O'Shea and Bartowiak-Théron, 2019; Cushion 2020) i.e., conceptual dilemmas.

For trainers with a 'traditional' linear, trainer-centred, skills first focus, SBT will require a fundamental shift in how they train. Indeed, as Belur et al. (2020) suggest the trainer's role in approaches, such as SBT, is notably different to traditional, trainer-focused models of police training (cf. Makin, 2016). This requires in-depth knowledge of learner-centred learning methods that are often contrary to the model under which trainers were themselves trained (Lettic, 2016; Koerner and Staller, 2019; Koerner and Staller, 2020; Belur et al., 2020); a shift to a more interactive, complex, and unpredictable learning environment (Werth, 2011; Cushion 2013; Cushion, 2020; Jenkins et al., 2020). Trainers are repositioned in training to stand back, observe more, act as a facilitator being less directive, to "live in the background ... which is a difficult role to assume when the instructor is used to being the focus" (King Stargel,
2010, p. 140; Belur et al., 2020). Paradoxically, trainers have to come out of their 'comfort zone' to see the big picture because training with SBT is more complex than traditional training, requiring greater preparation, more concentration and 'noticing', and an overall greater pedagogical responsibility (King Stargel 2010; Werth, 2011; Belur et al., 2020). As Belur et al. (2020) and Shipton (2012) argue, trainers must develop specific facilitation skills that requires more than providing 'hints' to unambiguous right answers, and instead trainers maybe required to model, scaffold, question, guide, advise, de-brief, converse, offer heuristics or conceptual structures (cf. Cushion, 2013; Lettic, 2016).

In education, Cremin (1961) notes that "in the hands of firstrate instructors, innovations worked wonders; in the hands of too many average teachers (sic trainers), however, they led to chaos" (p. 348). The quality and effectiveness of PST can be low (Waddington et al., 2006; Rajakaruna et al., 2017; Cushion, 2020; Staller et al., 2021). While having strong content knowledge ('what to teach') (Cushion, 2020), our experiences support the research in suggesting trainers are unable to facilitate scenarios well or conduct instructional conversations (cf. Rajakaruna et al., 2017) not knowing how, having never experienced sufficient guidance in trainer education, nor seen effective models in action (cf. Basham, 2014; Bennell et al., 2020; Shipton 2020). Indeed, Shipton (2020) notes that trainers wanted to be more effective at facilitating learning but did not possess the necessary skills (cf. Bennell et al., 2020). Also, some trainers did not see the value in developing these skills and were happy in a traditional training paradigm and not engaging with SBT, even when this was an espoused training approach in their organization (Werth 2011; Shipton 2012; Basham, 2014; Makin, 2016).

It is not only a dilemma to need additional pedagogical expertise (Shipton 2012, 2020; Basham, 2014; Rajakaruna et al., 2017; Belur et al., 2020), but utilizing SBT also requires in-depth subject knowledge (Cushion, 2013). Knowledge gaps can be challenging and can lead to frustration for trainers and officers (Lettic, 2016; Belur et al., 2020). Indeed, as Shulman (1987) in education argues knowledge and understanding are even more critical than for more traditional alternatives. Trainers need to be aware of 'teachingpoints' and the principles underlying them, as well as the variety of ways these can be looked at and developed in and through a scenario. For example, trainers lack of underpinning knowledge can be exposed in the planning process when designing scenarios and appropriate instructional strategies. Also, during training when trainers can struggle to step back and observe and find the manipulation or layering of learning through the scenario difficult, as we have found, becoming 'lost in the chaos'. For example, a trainer not understanding how, during a scenario, to modify or condition to bring out learning points or missing 'coachable moments' because everything is happening at full-speed.

The outcome of these pedagogical dilemmas is that training and the application of SBT becomes limited by the trainers' role frame (Schön, 1983). That is, the trainers' education, knowledge and experience of training 'frames' what is seen and the potential for learning (and change). Pedagogical dilemmas will shape how a trainer engages with practice and shape the possibilities for 
implementing SBT. There is an important interplay between knowledge, experience and practice. Limited knowledge constrains 'seeing' and diminishes action i.e., training is reactive, but within existing knowledge and understanding. Research in police training (cf. Cushion 2020; Koerner and Staller, 2020; O'Shea and Bartowiak-Théron, 2019) has shown that trainers are also more likely to stick with traditional methods, trainer-led and trainer-controlled PST, training is less dialogic and interactive, with officers as passive receivers of information from a one-directional transmission. In this case, traditional approaches are based on a lack of knowledge rather than specific opposition to SBT (Shipton, 2012; Basham, 2014; Koerner and Staller, 2020).

\section{CULTURAL DILEMMAS}

Trainers' pedagogical practices are always situated in a larger context which is more than the 'container' into which they are dropped (Cushion, 2013). Context includes backgrounds and physical abilities; roles and responsibilities, prior knowledge and experiences, program design, curriculum, and learning activities, all in addition to police history, cultures and structures (Loftus, 2010; Belur et al., 2020; Shipton, 2020). The complex interaction of these factors influences the meaning that trainers and officers make of the learning process. Such factors can impact the learning environment in overt and covert ways and can be powerful in terms of a tacitly understood framework of norms, expectations and values; a training culture (Wolfe et al., 2019; Belur et al., 2020; Cushion, 2020; Shipton, 2020).

Creating patterns of beliefs and practices in trainers that enable an application of SBT (or any innovative pedagogy) will inevitably require usurping dominant police training cultures (Charles, 2000; Karp and Stenmark, 2011; Cushion 2013, 2020; Belur et al., 2020), and developing a stronger training culture mentality (Wolfe et al., 2019). The difficulty of which was recognized by Charles (2000, p. viii) who in implementing a new learning model into police training required "an organizational transition of epic proportions". The influence of police culture was similarly identified as an impediment to newer, more innovative and 'better' training models because of a "subcultural preference towards traditional approaches" (Chappell, 2007, p. 501; Beighton et al., 2015; Karp and Stenmark, 2011; Wolfe et al., 2019).

Our experiences across this project to date have supported the notion that police training has a persistent and resilient culture (Werth, 2011) providing images for PST about what it means to be being trainers (knowledge holders) and learners (passive receivers) (Lettic, 2016; O'Shea and Bartowiak-Théron, 2019; Shipton, 2020). A culture that has remarkable continuities and inertia within police values, assumptions, and practice (Loftus, 2010; Beighton et al., 2015). With research in the United Kingdom reporting resulting in an extraordinary sameness in PST over time (Buttle, 2007; Cushion, 2020). PST features high levels of trainer-led instruction and a predominance of isolated, dis-integrated and repetitive 'drills', where trainers talk most of the time and officers listen (Waddington et al., 2006;
Buttle, 2007; Cushion, 2020; Staller et al., 2021)-skills need to be learned first, and training never starts with a scenario, they should be at the end, or as part of an assessment.

This overly controlled and trainer-led training culture is supported in-part by the trainers' beliefs; the simple and seductive premise of 'being-right' based on years of experience (Windschitl 2002). This has remained unchallenged because, as Shipton (2020) argues, effective change from authority driven trainer-centred practice towards evidence-based learner-centred practice has been restricted by the insulation of the police from the field of adult education, and the influence of policing subculture (Chan et al., 2003; Karp and Stenmark, 2011; Beighton et al., 2015; Wolfe et al., 2019). However, if PST is to 're-culture' (Windschitl, 2002) the first obstacle to overcome is the experiences of trainers and learners. As Gundhus (2013) argues, new knowledge regimes are often met with resistance, not only because of the stubbornness of police occupational culture, but because they threaten what is perceived, in this case by trainers, as their meaningful professional practices. Receptivity to change is impacted by practice that differs from traditional in-service experiences (Wolfe et al., 2019). In other words, a highly contextual discourse has emerged that imposes and enforces a 'correct way' to train and be a trainer of PST. Therefore, trainers authenticate certain types of collective knowledge, and a discourse used in training in this way helps create and re-create the training field, giving certain practices an entrenched legitimacy (Belur et al., 2020). Prior socialization along with established beliefs and traditions reinforce this image and validate and acknowledge practice as 'effective'. With research confirming that this becomes a self-confirming loop (Kaminski and Martin, 2000; Cushion 2020; Koerner and Staller, 2020) and beliefs regarding effective and appropriate training reproduce and reinforce the traditional approach (Basham, 2014). To enact meaningful change, therefore, requires trainers to, "confront experiential knowledge" (O'Shea and Bartowiak-Théron, 2019, p. 290; Wolfe et al., 2019).

This training culture can also be seen in terms of fulfilling the requirements of the training role. PST discourses have been reported as not being about effectiveness or skill development but prioritising managing time pressures and 'getting officers through' uninjured (cf. Cushion, 2020). This means a narrow view of training that excludes 'realistic' practices (Beighton et al., 2015; Cushion, 2020). Moreover, this overly cautious, or 'risk averse culture' (Heslop, 2011), is reflective of its conservative nature rather than genuine risk, but only serves to reinforce operational incompetence (Beighton et al., 2015; Cushion 2020). As a result, this sees the trainer attempting to control as many variables as possible, and this imperative of control is a habit that many police trainers bring to a traditionally militarized and behaviourist training context (White 2006; Shipton, 2020)-in our experiences of this project trainers have wrestled with letting go of control and re-positioning themselves to centre the scenario and the learners. This means 'tried and tested', traditional methods that prove trainer knowledge and expertise but also are considered 'safe'. The consequence of this is that officers are, in-turn, socialized into expecting a particular type of PST experience, and can resist other training methods (Wolfe 
et al., 2019). This has implications for cultural change as PST becomes a historical and traditional thread where experiences are powerful, long lasting, and have a continual influence over pedagogical perspectives, practices, beliefs and behaviours (Koerner and Staller, 2019; Koerner and Staller, 2020; Wolfe et al., 2019). The driver for practice is therefore not evidencebased learner-centred pedagogy, but often an inward-looking tradition (Lumsden, 2017), or uncritical inertia. This means that PST trainers, who are largely drawn from rank-and-file officers, already have an understanding of PST based on experience that filters new methods. Moreover, we have found that the in-depth knowledge of learner-centred learning methods that SBT requires are often contrary to the model under which trainers were themselves trained (cf. Lettic, 2016; Wolfe et al., 2019; Belur et al., 2020) and which they experienced as officers (Koerner and Staller, 2019, 2020; Wolfe et al., 2019).

\section{POLITICAL DILEMMAS}

Political dilemmas refer to those aspects of practice that are linked with the exercise, distribution, preservation, or redistribution of power among participants in an educational enterprise (Windschitl, 2002). Any innovative pedagogy, such as SBT, can generate controversy and possibly conflict. Indeed, there are strong differences in opinion surrounding changes to police training among its stakeholders (e.g., policy makers, trainers, management, officers, as well as the public) (Di Nota and Huhta 2019). As a result, updating police training can be met with controversy, despite evidence for the benefits of different training approaches (Di Nota and Huhta 2019; Wolfe et al., 2019), and a societal need for changes to policing practices (Makin, 2016; Di Nota and Huhta 2019). Moreover, trainer's practice reflects and refracts wider social forces from interested parties such as stakeholders, producers of knowledge, and wider society (Karp and Stenmark, 2011). Thus, doing SBT and its outcomes, as well as establishing a training environment conducive to implementing it, can have wider political implications.

While PST pedagogy has remained consistent over time and across organizations, O'Neil et al. (2019) observed that there can be considerable variability in the content and duration of PST between organizations, while Cushion (2020) reports within police organization variability. In the United Kingdom, similar to other countries (cf. O'Neil et al., 2019), the detailed choice of PST curriculum and pedagogy are currently devolved to forces. However, the College of Policing (CoP)-the national professional body for policing in England and Wales-is overhauling current PST and replacing it with a new national curriculum, including recommended contact time with trainers (College of Policing 2020) moving away from in-house driven training (Beighton et al., 2015; Lum and Koper 2015). Such organizational leadership and support are to be applauded as research shows that organizations can maximize the impact of training and play key roles when training is being developed and delivered (Bennell et al., 2020), and without organizational commitment, training is likely to be sub-optimal (e.g., Andersen et al., 2016; Belur et al., 2020; Bennell et al., 2020).
That said, using SBT to change PST will stand or fall on effective teaching and learning, therefore the need for quality trainers is paramount; trainers who are pedagogically imaginative, dynamic, and thoughtful, who think creatively about alternative ways of training, and are, as a result, better prepared to respond to the realities of their professional work. This requires considerable pedagogical authority and autonomy in trainers. However, there is a danger in standardizing and controlling practice with a national curriculum that homogenizes practice under the banners of modernization and professionalization (Lumsden 2017). Officers often portray policing as a craft where experiential learning and experienced officers are valorised (Lumsden, 2017). Centralized changes can expose tension and resistance between the police organization and street-level police occupational culture, demonstrating differences between management objectives and practitioner views (Gundhus 2013; Lumsden, 2017). Indeed, Heslop (2011) and Goode and Lumsden (2016) highlight the ways in which the police are becoming increasingly micro-managed, bureaucratic and risk averse, increasingly 'McDonaldized' (Goode and Lumsden, 2016). Indeed, any 'professionalization' of training appears problematic if PST curricula are overly controlled and defined higher up the administrative chain. For SBT in particular, trainers given standardized knowledge and strategies reduce scenarios to the application of a generic set of rules. We have found in line, with others (e.g., Rajakaruna et al., 2017; Jenkins et al., 2020), that this can be easily presented as a predictable linear process where scenarios become overly scripted 'walkthroughs' to a desired response devoid of perception, judgement and decision-making Paradoxically, while the police and their communities demand innovative and sophisticated training, arguably, national policy could inadvertently discourage such training, or build-in inadequacy into SBT (cf. Rajakaruna et al., 2017).

Debate among policy makers, trainer education and trainers about the logic of the means (how and what) of training also diverts attention from more fundamental questions about the nature and aims of training (why and who for) (Cushion, 2013). PST is currently very focused and specific, but has a narrow operational focus attempting to transmit and develop proficiency in a series of skills and techniques, (Rostker et al., 2008; Morrison and Garner, 2011; Rajakaruna et al., 2017). However, in addition to its overt curriculum, an informal or 'hidden curriculum' exists, a set of implicit messages that officers experience in and through training processes which reinforce or challenge attitudes, values, and expectations (Cooper, 2009; Cushion, 2020). Police training contributes to the production and reproduction of social structures through its 'hidden curriculum' (cf. White, 2006), including derogatory discourses that can denigrate and stigmatize (Beighton et al., 2015). In PST, for example, promoting 'hyper-masculinity' and sexism (Cushion, 2020), as well as an over-focus on danger and authority (Constable and Smith, 2015) to the detriment of the effectiveness of training for all and a more expansive understanding of training and the police officer role (Constable and Smith, 2015; Cushion, 2020). Consequently, police training is an inescapably political act, not apolitical or neutral. 
Tradition provides an overriding, powerful, and historical view of what trainers should do and what training should look like (Beighton et al., 2015; O’Shea and Bartowiak-Théron 2019). Innovative pedagogy, despite being evidence-based, suffers an underlying disadvantage as it can be viewed as a questionable alternative to existing practice (cf. Windschitl, 2002; Wolfe et al., 2019). The durability of this notion is evidenced through SBT with over thirty years of history, and problem-based approaches in wider education existing even longer than this, remains a training 'alternative'. Indeed, police training discourse (of which this paper is a part) privileges the status quo by associating training models where skills are mastered first with 'traditional', 'historical', and 'fundamental' training, while SBT is 'alternative' or 'innovative', thus forming a subtle but coherent set of rationalities. Therefore, far from being benign activities, training and trainer education, always contain and advance values and agendas. As such, implementing SBT and critically examining and challenging beliefs, practices, and discourse becomes political. SBT challenges existing assumptions and therefore beliefs about learning and knowledge about training practice becomes less absolute. Consequently, trainers are forced to confront their own uncertainties, and even their own inadequacies, and as training and trainer education exists in organisations, the status quo becomes threatened making stakeholders uneasy, uncomfortable and even resistant (cf. Loftus, 2010; Gundhus, 2013; Goode and Lumsden, 2016).

\section{DISCUSSION}

Windschitl's (2002) dilemmas are a useful heuristic to illustrate the complexity of training, and the multiple and layered issues that must be confronted to implement change. The categories show the precarious nature of implementing SBT to develop PST, and the issues that can influence the likelihood of innovative pedagogies surviving, being resisted or eventually 'washed out'. Importantly, this paper demonstrates that 'knowledge' of SBT, even its applied principles, is insufficient, and that implementation involves more than simply providing trainers with a 'toolbox' of skills and a 'list of scenarios'. Operationalizing SBT for PST requires a host of knowledge, understanding, practices, strategies, coherent arguments, and critical thinking, all of which are conspicuously absent from trainer education and the rhetoric of trainer development (e.g., Berg, 1990; McCoy, 2006; Werth, 2011; Shipton, 2012, 2020). Arguably, implementing authentic SBT and, for example, starting training with a scenario is so conspicuous, so unlike typical training, that it becomes subjected to an unwarranted level of scrutiny and subject to an intensification of accountability. However, in reality traditional, linear, 'block and checklist' (O'Neil et al., 2019) approaches do not currently face a similar level of challenge and, as Windschtil argues, "although perennially ineffective are rarely subjected to fundamental critique" (2004, p.160).

So, the challenges to implement SBT as a vehicle to change PST seem significant. Of course, as we have found, some trainers can successfully employ SBT and reflect upon and change the nature of their training practice (Werth, 2011). How can training ensure the implementation of innovative pedagogy and the development by design of these kinds of skilled trainers? Research indicates that currently 'train-thetrainer' training typically delivers content knowledge rather than the ability to facilitate learning processes (e.g., Berg, 1990; McCoy, 2006; Werth, 2011; Shipton, 2012, 2020), where development is seen almost exclusively as expanding and presenting content knowledge. Whilst it is recognized developing content knowledge is vital for any police trainer, this limits capacity for them to promote deeper learning (McCoy 2006; Shipton, 2020). This model does not address the conceptual or pedagogical dilemmas of practice as it is inadequate in giving trainers an awareness of their own beliefs and assumptions about training, developing an understanding of learning. Such an approach, with its very narrow and technical focus, does not address the complexities of practice and therefore does not broach the social, cultural, and political dilemmas of training practice. Indeed, it is necessary to be aware of the assumptions about learning that underpin any method of teaching, particularly when such assumptions challenge beliefs about learning (Cushion, 2013). However, there remains a considerable challenge to address trainer's conceptual dilemmas created through the embodied and unarticulated beliefs about learning and training. SBT can invoke initial scepticism because it confronts these beliefs (Irby, 1996; Shipton, 2012), thus presenting the dual challenge of transforming beliefs about training and learning whilst also providing specific training/ facilitation skills. To address these conceptual dilemmas, trainer education, and train-the-trainer, therefore, needs to provide an environment where practice and the practice of others can be interrogated, and assumptions made explicit. Uncovering assumptions and beliefs emancipates practitioners from their dependence on habit and tradition providing them with the skills and resources to enable reflection and to examine critically the inadequacies of different conceptions of practice (Carr and Kemmis, 1986; Cushion, 2013) and thus address pedagogical dilemmas. However, learning in this way is beyond existing conceptions of trainer education which is an additive, 'retooling' according to behavioural assumptions (grafting new 'skills'/knowledge onto an existing repertoire) (Beighton et al., 2015) rather than a critically transformative (deconstructing taken-for-granted beliefs, assumptions, knowledge and habits, and rebuilding practice) move away from assimilation, dissemination and application (Beighton et al., 2015; Shipton, 2020).

To problematize ideas about training, in addition to information about SBT, trainers could benefit from case examples from other trainers illustrating the experiences of those who have attempted to change PST practice and culture. Currently, existing research and guidance about SBT is useful (e.g., Hine et al., 2018; Bennell et al., 2020; Jenkins et al., 2020) but remains compelling rhetoric and too idealized, providing prescriptive lists, principles, and decontextualized examples, that do not engage with the issues and challenges of 'doing' training in context. To address pedagogical dilemmas head on 
trainer education should (correctly) model context specific SBT, enabling understanding of the increasing complex and representative layering of learning through versions of the whole, as well as the array of modification principles. Trainers require in-situ support in understanding differences between their existing practice, attempts at SBT, and authentic SBT and recognizing the distance between existing practice and understanding.

In developing SBT, and in addition to education and development, trainers must also create opportunities to speak with others. Communities of practice (CoP) (Lave and Wenger, 1991) are a means to understand and structure trainer learning (cf. Jenkins et al., 2020). While the rhetoric of communities of practice is appealing, the reality of trainers' lives can make them difficult to sustain within the nature of day-to-day police training routines and regularities that can promote trainer isolation. Where trainers do discuss training, this often remains at an instrumental level merely passing on 'survival tips' or 'tricks of the trade', leaving unexamined and unchallenged contextual norms and culture, thus not addressing cultural and political dilemmas of practice. Ways to initiate and mediate new kinds of conversations are needed, and partnerships and coalitions to create a critical mass within a community to advance ideas and thinking are required. Such an approach holds the promise of deeper, reflective conversations that foreground cultural and political dilemmas of practice.

\section{REFERENCES}

Alison, L., van den Heuvel, C., Waring, S., Power, N., Long, A., O’Hara, T., et al. (2013). Immersive Simulated Learning Environments for Researching Critical Incidents. J. Cogn. Eng. Decis. Making 7 (3), 255-272. doi:10.1177/ 1555343412468113

Andersen, J. P., and Gustafsberg, H. (2016). A Training Method to Improve Police Use of Force Decision Making: A Randomized Controlled Trial. J. Police Emerg. Response 6 (2), 8708. doi:10.1177/2158244016638708

Andersen, J. P., Pitel, M., Weerasinghe, A., and Papazoglou, K. (2016). Highly Realistic Scenario-Based-Training Simulates the Psychophysiology of RealWorld Use of Force Encounters: Implications for Improved Police Officer Performance. J. L. Enforcement 5 (4), 1-13.

Basham, B. R. (2014). Police Instructor or Police Educator? Salus J. 2 (1), 99-109.

Beighton, C., Poma, S., and Leonard, V. (2015). Expansive Learning in Firearms Training: the HE/professional Learning Interface. Police Pract. Res. 16 (5), 378-390. doi:10.1080/15614263.2014.951045

Belur, J., Agnew-Pauley, W., McGinley, B., and Tompson, L. (2020). A Systematic Review of Police Recruit Training Programmes. Policing: A J. Pol. Pract. 2020, 1-15. doi:10.1093/police/paz022

Bennell, C., Blaskovits, B., Jenkins, B., Semple, T., Khanizadeh, A.-J., Brown, A. S., et al. (2020). Promising Practices for De-escalation and Use-Of-Force Training in the Police Setting: a Narrative Review. Policing Int. J. Police Strateg. Manage. 44, 377-404. doi:10.1108/PIJPSM-06-2020-0092

Berg, B. L. (1990). Who Should Teach Police: A Typology and Assessment of Police Academy Instructors. Am. J. Police 9, 79-100.

Bergman, B., Karp, S., and Widding, U. (2018). Educating Police Officers in Sweden: All about Making Meaning. Eur. J. Policing Stud.

Birzer, M. L., and Tannehill, R. (2001). A More Effective Training Approach for Contemporary Policing. Police Q. 4 (2), 233-252. doi:10.1177/ 109861101129197815

Birzer, M. L. (2003). The Theory of Andragogy Applied to Police Training. Policing 26 (1), 29-42. doi:10.1108/13639510310460288

\section{CONCLUSION}

The very features that render any innovative pedagogy such as SBT effective in training practice are those that provide most challenge and the catalyst for practice dilemmas. When used in an uncritical or unsophisticated way, or fragmented and promoted with pseudoprinciples and little understanding, any innovative pedagogy will struggle to gain traction and acceptance. However, when practice is premised on authentic SBT, it can be an important catalyst for change (Beighton et al., 2015; Bergman et al., 2018; Belur et al., 2020; Bennell et al., 2020). To challenge and change existing practice requires a 'jointly fashioned vision of transformation' (Windschitl, 2002), with academics, trainers, and trainer educators working in partnership to deliver education and training (cf. Beighton et al., 2015; O’Shea and Bartowiak-Théron 2019; Wolfe et al., 2019; Belur et al., 2020; Shipton, 2020). Such an alliance should provide the theoretical knowledge and practice tools to convert dilemmas into attributes that facilitate the development of PST and the realization of SBT. This is a vision of practitioners that Windschitl, (2002) describes as having conceptual understanding, pedagogical expertise, cultural consciousness and political acumen.

\section{AUTHOR CONTRIBUTIONS}

The author confirms being the sole contributor of this work and has approved it for publication.

Broomé, R. E. (2011). An Empathetic Psychological Perspective of Police Deadly Force Training. J. Phenomenol Psychol. 42 (2), 137-156. doi:10.1163/ $156916211 \times 599735$

Bruner, J. (1999). "Folk Pedagogies," in Learners and Pedagogy. Editors B. Leach and B. Moon (London: Open University Press), 4-20.

Buttle, J. W. (2007). A Constructive Critique of the Officer Safety Programme Used in England and Wales. Policing Soc. 17 (2), 164-181. doi:10.1080/ 10439460701302735

Carpenter, S. K., Cepeda, N. J., Rohrer, D., Kang, S. H. K., and Pashler, H. (2012). Using Spacing to Enhance Diverse Forms of Learning: Review of Recent Research and Implications for Instruction. Educ. Psychol. Rev. 24 (3), 369-378. doi:10.1007/s10648-012-9205-Z

Carr, W., and Kemmis, S. (1986). Becoming Critical. Basingstoke: Taylor and Francis.

Chan, J. B. Devery, C., and Doran, S. (2003). Fair Cop: Learning the Art of Policing. Toronto: University of Toronto Press.

Charles, M. T. (2000). Police Training: Breaking All the Rules. Implementing the Adult Education Model into Police Training. Springfield, Illinois: Charles C Thomas Publisher.

Chappell, A. T. (2007). Community policing: is field training the missing link?. Policing: An International Journal 30 (3), 498-517. doi:10.1108/ 13639510710778868

Clarke, C. A., and Armstrong, K. (2021). "Beyond reproach: The need for effective and responsive training," in Police organisation and training: Innovations in research and practice. Editors M. R. Haberfield, C. A. Clarke, and D. L. Sheehan (New York, NY: Springer Science and Business Media), 11-16.

Cleveland, G., and Saville, G. (2007). Police PBL: Blueprint for the 21st Century. Police Society for Problem Based Learning. Available at: http://www.pspbl.com/ pdf/PolicePBLBook2007.pdf.

College of Policing (2020). NPCC and College of Policing Pledge to Improve Officer and Staff Safety. Available at: https://www.college.police.uk/article/ npcc-and-college-policing-pledge-improve-officer-and-staff-safety.

Constable, J., and Smith, J. (2015). "Initial Police Training and the Development of Police Occupational Culture," in Police Services: Leadership and Management 
Perspectives. Editors D. Wankhade and P. Weir, 45-60. doi:10.1007/978-3-31916568-4_4

Cooper, F. R. (2009). 'Who's the Man?': Masculinities Studies, Terry Stops and Police Training. Boston, MA, USA: Suffolk University Law School Faculty Publications, 57.

Cremin, L. (1961). The Transformation of the School: Progressivism in American Education 1876-1957. New York: Vintage Books.

Cushion, C. (2020). Exploring the Delivery of Officer Safety Training: A Case Study. Policing (Oxford) A J. Pol. Pract. 14 (1), 166-180. doi:10.1093/police/ pax095

Cushion, C. J. (2013). Applying Game Centered Approaches in Coaching: a Critical Analysis of the 'dilemmas of Practice' Impacting Change. Sports Coaching Rev. 2 (1), 61-76. doi:10.1080/21640629.2013.861312

Davis, B., and Sumara, D. (2003). Why Aren't They Getting This? Working through the Regressive Myths of Constructivist Pedagogy. Teach. Educ. 14 (2), 123-140. doi:10.1080/1047621032000092922

Di Nota, P. M., and Huhta, J. M. (2019). Complex Motor Learning and Police Training: Applied, Cognitive, and Clinical Perspectives. Front. Psychol. 10, 1797. doi:10.3389/fpsyg.2019.01797

Fullan, M. (1991). The New Meaning of Educational Change. New York: Teachers College Press.

Goode, J., and Lumsden, K. (2016). The McDonaldisation of Police-Academic Partnerships: Organisational and Cultural Barriers Encountered in Moving from Research on Police to Research with Police. Policing Soc. 28, 75-89. doi:10.1080/10439463.2016.1147039

Gundhus, H. I. (2013). Experience or Knowledge? Perspectives on New Knowledge Regimes and Control of Police Professionalism. Policing 7, 178-194. doi:10.1093/police/pas039

Heslop, R. (2011). Reproducing Police Culture in a British university: Findings from an Exploratory Case Study of Police Foundation Degrees. Police Pract. Res. 12 (4), 298-312. doi:10.1080/15614263.2011.563966

Hine, K. A., Porter, L. E., Westera, N. J., Alpert, G. P., and Allen, A. (2018). Exploring Police Use of Force Decision-Making Processes and Impairments Using a Naturalistic Decision-Making Approach. Criminal Justice Behav. 45 (11), 1782-1801. doi:10.1177/0093854818789726

Hulsof, M., and Spapens, R. (2014). Training Arrest and Self-Defence Skills with Law Enforcement (Politie VU: University of Amsterdam). Unpublished MSc dissertation.

Irby, D. M. (1996). Models of Faculty Development for Problem-Based Learning. Adv. Health Sci. Educ. 1, 69-81. doi:10.1007/bf00596230

Jager, J., Klatt, T., and Bliesener, T. (2013). NRWStudie: Gewalt gegen Polizeibeamtinn en und Polizeibeamte. Kiel, Germany: Department of Psychology, Christian-Albrechts-University.

Jenkins, B., Semple, T., and Bennell, C. (2020). An Evidence-Based Approach to Critical Incident Scenario Development. Pijpsm 44, 437-454. doi:10.1108/ PIJPSM-02-2020-0017

Kaminski, R. J., and Martin, J. A. (2000). An Analysis of Police Officer Satisfaction with Defence and Control Tactics. Policing: Int. J. Police Strategy Manage. 23 (2), 123-153. doi:10.1108/13639510010333697

Karp, S., and Stenmark, H. (2011). Learning to Be a Police Officer. Tradition and Change in the Training and Professional Lives of Police Officers. Police Pract. Res. 12 (1), 4-15. doi:10.1080/15614263.2010.497653

King Stargel, T. M. (2010). The Perceived Value of Problem-Based Learning at a Police Training Academy (Seattle, Washington: Seattle University). Ph.D. thesis.

Kirschner, P. A., Sweller, J., and Clark, R. E. (2006). Why Minimal Guidance during Instruction Does Not Work: An Analysis of the Failure of Constructivist, Discovery, Problem-Based, Experiential, and Inquiry-Based Teaching. Educ. Psychol. 41 (2), 75-86. doi:10.1207/s15326985ep4102_1

Koedijk, M., Renden, P. G., Oudejans, R. R. D., and Hutter, R. I. V. (2019). Training for the Job: Evaluation of a Self-Defence Training Programme for Correctional Officers. Ergonomics 62 (12), 1585-1597. doi:10.1080/00140139.2019.1677947

Koerner, S., and Staller, M. S. (2020). Police Training Revisited-Meeting the Demands of Conflict Training in Police with an Alternative Pedagogical Approach. Policing 15, 927-938. doi:10.1093/police/paaa080

Koerner, S., and Staller, M. S. (2019b). "“'Weil Mein Background da War. . .” Biographische Effekte Bei Einsatztrainerinnen' ['Because my Background Was. . . “- Biographical Career Effects of Operational Trainers']," in Teaching Is Learning: Methods, Contents and Role Models in the Didactics of Martial Arts - 8th Annual Symposion of the Dvs-Komission. Editors M. Meyer and M. S. Staller (Vechta: Kampfkunst Und Kampfsport), 13-14.

Lave, J., and Wenger, E. (1991). Situated Learning: Legitimate Peripheral Participation. Cambridge: Cambridge University Press.

Lettic, S. (2016). Problem Based Learning (PBL) in Police Training: An Evaluation of the Recruit Experience (Minneapolis, MN: Capella University). Ph.D.thesis.

Loftus, B. (2010). Police Occupational Culture: Classic Themes, Altered Times. Policing Soc. 20 (1), 1-20. doi:10.1080/10439460903281547

Lum, C., and Koper, C. S. (2015). "Evidence-Based Policing," in Critical Issues in Policing. Editors R. G. Dunham, and G. P. Alpert. Seventh Edition (Long Gove, IL: Waveland Press), 1-15.

Lumsden, K. (2017). 'It's a Profession, it Isn't a Job': Police Officers' Views on the Professionalisation of Policing in England. Sociological Res. Online 22 (3), 4-20. doi:10.1177/1360780417724062

Makin, D. A. (2016). A Descriptive Analysis of a Problem-Based Learning Police Academy. Interdiscip. J. Problem-Based Learn. 10 (1), 1544. doi:10.7771/15415015.1544

Mayer, R. E. (2004). Should There Be a Three-Strikes Rule against Pure Discovery Learning? the Case for Guided Methods of Instruction. Am. Psychol. 59 (1), 14-19. doi:10.1037/0003-066X.59.1.14

McCoy, M. R. (2006). Teaching Style and the Application of Adult Learning Principles by Police Instructors. Policing 29 (1), 77-91. doi:10.1108/ 13639510610648494

Miller, J., and Alexandrou, B. (2016). College of Policing Stop and Search experiment; Impact Evaluation. London: College of Policing.

Morrison, G. B., and Garner, T. K. (2011). Latitude in Deadly Force Training: Progress or Problem? Police Pract. Res. 12 (4), 341-361. doi:10.1080/ 15614263.2011 .563968

Murray, K. R. (2004). Training at the Speed of Life, Volume One: The Definitive Textbook for Military and Law Enforcement Reality-Based Training. Gotha, FL: Armiger Publications.

O'Neil, J., O'Neil, A., Weed, K., Hartman, M. E., Spence, W., and \&Lewinski, W. (2019). Police Academy Training, Performance, and Learning. Behav. Anal. Pract. 12, 353-372.

O'Shea, B., and Bartkowiak-Théron, I. (2019). Being a Topic Expert Is Not Sufficient: a Mixed-Method Analysis of Teaching Dynamics at the Tasmania Police Academy. Police Pract. Res. 20 (3), 288-299.

Piggott, D. (2012). Coaches' Experiences of Formal Coach Education: a Critical Sociological Investigation. Sport Educ. Soc. 17, 535-554. doi:10.1080/ 13573322.2011.608949

Preddy, J. E., Stefaniak, J. E., and Katsioloudis, P. (2019). Building a Cognitive Readiness for Violent Police-Citizen Encounters: A Task Analysis. Perf Improvement Qrtly 32 (1), 55-76. doi:10.1002/piq.21288

Rajakaruna, N., Henry, P. J., Cutler, A., and Fairman, G. (2017). Ensuring the Validity of Police Use of Force Training. Police Pract. Res. 18 (5), 507-521. doi:10.1080/15614263.2016.1268959

Renden, P. G., Landman, A., Geerts, S. F., Jansen, S. E., Faber, G. S., Savelsbergh, G. J., et al. (2014). Effects of Anxiety on the Execution of Police Arrest and SelfDefense Skills. Anxiety Stress Coping 27 (1), 100-112. doi:10.1080/ 10615806.2013.810213

Renden, P. G., Landman, A., Savelsbergh, G. J., and Oudejans, R. R. (2015b). Police Arrest and Self-Defence Skills: Performance under Anxiety of Officers with and without Additional Experience in Martial Arts. Ergonomics 58 (9), 1496-1506. doi:10.1080/00140139.2015.1013578

Renden, P. G., Nieuwenhuys, A., Savelsbergh, G. J., and Oudejans, R. R. (2015a). Dutch Police Officers' Preparation and Performance of Their Arrest and SelfDefence Skills: a Questionnaire Study. Appl. Ergon. 49, 8-17. doi:10.1016/ j.apergo.2015.01.002

Rosenbaum, D. P., and Lawrence, D. S. (2017). Teaching Procedural justice and Communication Skills during Police-Community Encounters: Results of a Randomized Control Trial with Police Recruits. J. Exp. Criminol 13 (3), 293-319. doi:10.1007/s11292-017-9293-3

Rostker, B. D., Hanser, L. M., Hix, W. M. Jensen, C. Morral, A. R., Ridgewat, G., et al. (2008). Evaluation of the New York City Police Department Firearm Training and Firearm-Discharge Review Process. Santa Monica, CA: RAND Corporation.

Ryan, C. M. (2006). "Dry Your Eyes Princess : an Analysis of Gender and 'other' Based Discources in Police Organisations," in AARE 2006 : Conference Papers, 
Abstracts and Symposia (Coldstream, Vic: Australian Association for Research in Education), 1-14.

Schön, D. (1983). The Reflective Practioner: How Practitioners Think in Action. San-Fransisco: Harper Collins.

Shipton, B. (2012). Expanding Police Educators' Understanding of Teaching, Are They as Learner-Centred as They Think? J. Learn. Des. 4 (2), 1-19. doi:10.5204/ jld.v4i2.71

Shipton, B. (2020). Moving outside the comfort Zone: Teacher's Experiences of Development in a Police Academy Context. Stud. Contin. Educ. 2020, 1-17. doi:10.1080/0158037X.2020.1759524

Shulman, L. (1987). Knowledge and Teaching:Foundations of the New Reform. Harv. Educ. Rev. 57 (1), 1-23. doi:10.17763/haer.57.1.j463w79r56455411

Soderstrom, N. C., and Bjork, R. A. (2015). Learning versus Performance: An Integrative Review. Perspect. Psychol. Sci. 10 (2), 176-199. doi:10.1177/ 1745691615569000

Staller, M., Koerner, S., Heil, V., and Klemmer, I. (2021). The Structure and Delivery of Police Use of Force Training - A German Case Study. Eur. J. Security Res. 2021, 1078. doi:10.1007/s41125-021-00073-5

Staller, M. S., and Körner, S. (2019). Commentary: Complex Motor Learning and Police Training: Applied, Cognitive, and Clinical Perspectives. Front. Psychol. 10, 2444. doi:10.3389/fpsyg.2019.02444

Staller, M. S., and Zaiser, B. (2015). Developing Problem Solvers: New Perspectives on Pedagogical Practices in Police Use of Force Training. J. L. Enforcement 4 (3), 1-15.

Todak, N., and James, L. (2018). A Systematic Social Observation Study of Police De-escalation Tactics. Police Q. 21 (4), 509-543. doi:10.1177/ 1098611118784007

Waddington, P. A. J., Badger, D., and Bull, R. (2006). The Violent Workplace. London: Routledge.

Waddington, P. (1999). Police (Canteen) Sub-culture. An Appreciation. Br. J. Criminology 39, 287-309. doi:10.1093/bjc/39.2.287

Werth, E. P. (2011). Scenario Training in Police Academies: Developing Students' Higher-Level Thinking Skills. Police Pract. Res. 12 (4), 325-340. doi:10.1080/ 15614263.2011.563970

Wheller, L., QuintonFildes, P. A., and Mills, A. (2013). The Greater Manchester Police Procedural justice Training experiment: The Impact of Communication Skills Training on Officers and Victims of Crime. Wolsingham, England: College of Policing, UK.
Wheller, L., and Morris, J. (2010). What Works in Training and Behaviour Change and Implementing Guidance. London: National Police Improvement Agency (NPIA): Research, Analysis and Information Unit (RAI), UK.

White, D. (2006). A Conceptual Analysis of the Hidden Curriculum of Police Training in England and Wales. Policing Soc. 16, 386-404. doi:10.1080/ 10439460600968164

Wickens, C. D., Hutchins, S., Carolan, T., and Cumming, J. (2013). Effectiveness of Part-Task Training and Increasing-Difficulty Training Strategies: a MetaAnalysis Approach. Hum. Factors 55 (2), 461-470. doi:10.1177/ 0018720812451994

Windschitl, M. (2002). Framing Constructivism in Practice as the Negotiation of Dilemmas: An Analysis of the Conceptual, Pedagogical, Cultural, and Political Challenges Facing Teachers. Rev. Educ. Res. 72 (2), 131-175. doi:10.3102/ 00346543072002131

Wolfe, S. E., McLean, K., Rojek, J., Alpert, G. P., and Smith, M. R. (2019). Advancing a Theory of Police Officer Training Motivation and Receptivity. Justice Q. 2019, 1-23. doi:10.1080/07418825.2019.1703027

Wollert, T. N., and Quail, J. (2018). A Scientific Approach to Reality Based Training. Winnipeg, Manitoba: Three Pistols Publishing.

Young, M. (1991). An inside Job. Oxford: Clarendon Press.

Conflict of Interest: The author declares that the research was conducted in the absence of any commercial or financial relationships that could be construed as a potential conflict of interest.

Publisher's Note: All claims expressed in this article are solely those of the authors and do not necessarily represent those of their affiliated organizations, or those of the publisher, the editors and the reviewers. Any product that may be evaluated in this article, or claim that may be made by its manufacturer, is not guaranteed or endorsed by the publisher.

Copyright (C) 2022 Cushion. This is an open-access article distributed under the terms of the Creative Commons Attribution License (CC BY). The use, distribution or reproduction in other forums is permitted, provided the original author(s) and the copyright owner(s) are credited and that the original publication in this journal is cited, in accordance with accepted academic practice. No use, distribution or reproduction is permitted which does not comply with these terms. 